\title{
Duodenal Duplication of Unusual Discovery: Case Report Chambéry Hospital French
}

\author{
Konate Madiassa, Traore Amadou, Dembele Bakary Tiéntigui, Karembe Boubacar, \\ Amadou Issa, Mangane Moustaphissa, Diop Thierno Madani, Togo Adégnepierre, \\ Kante Lassana, Traore Alhassane, Bah Amadou, Sidibe Boubacaryoro, Diamoutene Kolo, \\ Samake Moussa, Mounimezié Diarra, Diakite Ibrahim, Coulibaly Yacaria, Keita Soumaila, \\ Legros Jean Remy Mattia Stella, Demane Sofiane, Al Naasan Irchid, Diallo Gangaly
}

Faculty of Medicine and Odonto-Stomatology, Bamako, Mali

Email: *konate8@gmail.com

How to cite this paper: Madiassa, K., Amadou, T., Tiéntigui, D.B., Boubacar, K., Issa, A. Moustaphissa, M., Madani, D.T., Adégnepierre, T., Lassana, K., Alhassane, T., Amadou, B., Boubacaryoro, S., Kolo, D. Moussa, S., Diarra, M., Ibrahim, D., Yacaria, C., Soumaila, K., Stella, L.J.R.M., Sofiane, D., Irchid, A.N. and Gangaly, D. (2018) Duodenal Duplication of Unusual Discovery: Case Report Chambéry Hospital French. Surgical Science, 9, 222-226.

https://doi.org/10.4236/ss.2018.97026

Received: May 3, 2018

Accepted: July 14, 2018

Published: July 17, 2018

Copyright $\odot 2018$ by authors and Scientific Research Publishing Inc. This work is licensed under the Creative Commons Attribution International License (CC BY 4.0).

http://creativecommons.org/licenses/by/4.0/

\begin{abstract}
We report the case of a 33-year-old man having presented the episodes of abdominal pains since a few months in 2014. He was handled by the analgesic and the anti spasmodic by his regular doctor. Symptoms in started up again with renewed vigor in February, 2015. The physical examination was normal. The complementary examinations must be known by the ultrasound the scanner and the magnetic resonance imaging which were in favour of a mass under person suffering from a liver complaint the normal blood balance assessment. The patient was exclusively operated by the way of coelioscopy and the anatomopathology examination of the operating room ended has a duplication duodenal. The operating consequences were simple until one year.
\end{abstract}

\section{Keywords}

Duplication, Duodenal, Hospital, Chambéry, French

\section{Introduction}

The duodenal duplication is a rare embryological defect because it concerns only 4/10 million births [1]. It can appear as an intestinal obstruction, acute pancreatitis, a perforation, a digestive bleeding, a ferripriveanaemia or after a trauma [2].

It appears most of the time in the childhood and the classic treatment is the surgical resection [3].

We report here the case of 33 years old man after episodes of abdominal pains. Abdominal ultrasound objectified a mass below the liver. 


\section{Observation}

A man of 33 years old presented an abdominal pain since November, 2014.

An abdominal pain of moderate intensity has type of gravity sits épigastrique without triggering factor nor aggravating calmed by analgesic landing two.

Pain without irradiation and without signs of support (no nausea nor vomiting no disorders of the transit no regurgitation). He was treated by his regular doctor.

During the third episodes of pain an abdominal ultrasound highlighted an elongated mass of $7 \mathrm{~cm}$ below the liver.

The patient has history of high blood pressure. He was not a diabetic or obese man/There was no history of congenital malformation in the family.

The physical examination is almost normal

$$
\mathrm{WHO}=0 \mathrm{BMI}=30
$$

A blood pressure has $12 / 7$ a temperature has $37^{\circ} \mathrm{C}$ the pulse has 85 pulsations by minutes.

Blood balance sheet was normal.

Injected abdominal scanning highlighted a cystic lesion of $10 \mathrm{~cm}$ of diameter at the level of the second duodenum (Figure 1).

A magnetic resonance imaging objectified a mass of $7 \mathrm{~cm}$ of diameter below the liver without continuity with the biliary tract (Figure 2).

The endoscopic ultrasound found a duodenal cystic image. The puncture biopsy was not contributory.

We decided to do the surgery by laparoscopy. He was operated on February 28th, 2015.

During operation we discovered a cystic lesion of $15 \mathrm{cms} \times 6 \mathrm{cms}$, the wall of which seems to be digestive at the laparoscopy (Figure 3 \& Figure 4). A total ablation was exclusively realized under coelioscopy. The contents were liquid and solid. After the opening of the operative piece we discover a very plentiful whitish substance.

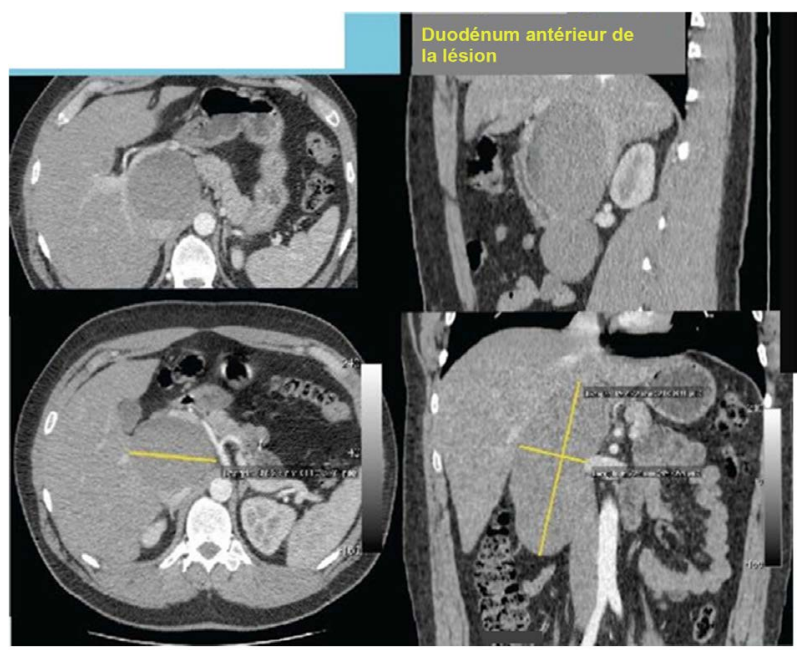

Figure 1. Scanograpgic image. 


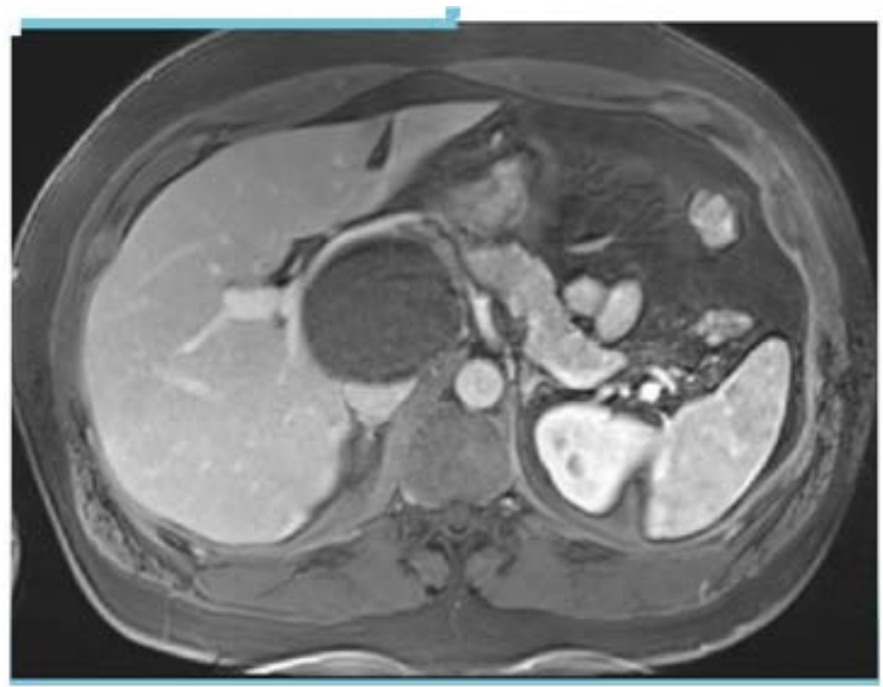

Figure 2. MRI Cystic mass.

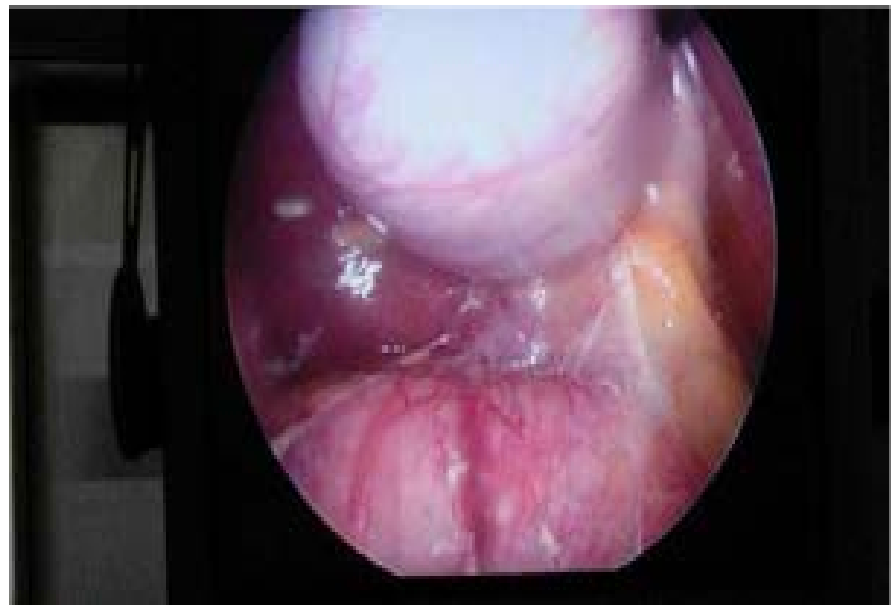

Figure 3. Cystic image during coelisocopy.

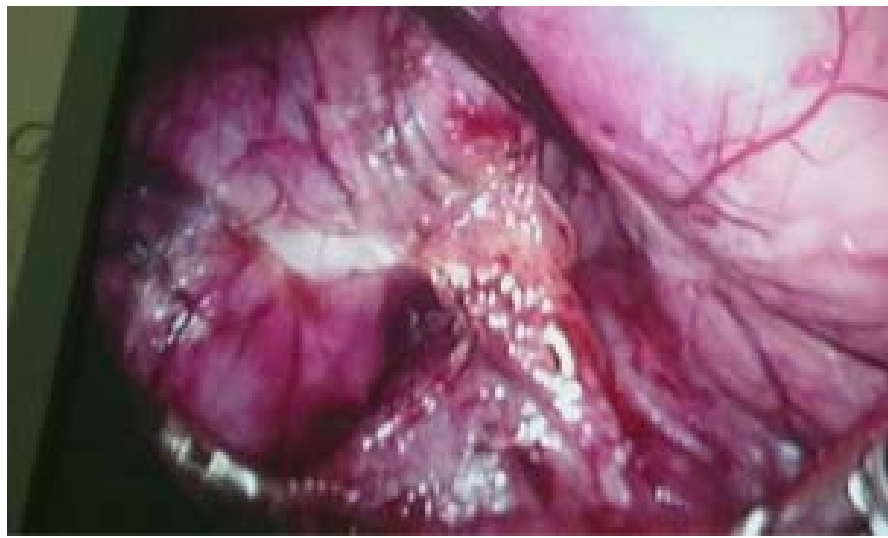

Figure 4. Cystic image during coelisocopy.

The anatomopathology found cystic lesion with a digestive wall concluding to a duodenal duplication without malignant sign. 


\section{Discussion}

Duodenal duplication is an extremely rare pathology. It represents $4 \%$ of all digestive tract congenital malformations [1]. It is often associated with other anomalies (intestinal malrotation, scalloped vertebras) [2]. Our case was isolated.

It is a benign histological pathology although two cases of malignant transformations within a duodenal cystic duplication were reported in the literature. In one of the two cases, the degeneration arose on mucous membrane of gastric type within the cyst of duplication and in the second it was duodenal mucous membrane [2] [3]. The diagnosis of cancer was made in both cases on the surgical pieces at anatomopathology. There had been no biopsy within the cyst.

This malformation appears in $70 \%$ of the cases before one year of the age but the late revelation is possible [4] like the case in our patient. The digestive obstruction is the most frequent mode of revelation. Acute pancreatitis was reported and sometimes the diagnosis can be delayed many years.

The duodenal duplication, the anomaly of the embryogenesis, is diagnosed most of the time in the childhood, even by prenatal diagnosis [5]. The average age at the time of the diagnosis is from four months to nine years. Prevalence is lightly in favour of the male [6]. It is a benign congenital defect, acquired during the embryonic development of the digestive tract [7]. It represents $5 \%$ to $12 \%$ of all the gastro-intestinal duplications [8]. The spherical form is much more frequent than the tubular one, and the duodenal way is kept.

The histology finds muscular mucous made of two smoother muscular coats and a mucous membrane of digestive type [9]. It is the histology which confirms the diagnosis of duodenal duplication. It can be found, on all the digestive tract (from the mouth to the anus). The colorectal forms can be of later discovery [4]. There are most of the time vertebral varied associated deformations [4]. The revealing clinical signs are not specific related to the complications: high intestinal obstruction, digestive bleeding [1], recurrent acute pancreatitis [2] [5], regurgitations in the infant [4] or vomiting [3] [4], and tender abdomen with a tangible mass of upper abdominal quadrant [6]. We did not find published case of traumatic rupture of a duodenal duplication. The diagnosis can be evoked during the prenatal period [4]. The complementary examinations are essentially radiological. The main complementary examinations of imaging necessary for the preoperative diagnosis are the abdominal ultrasound or echo endoscopy with biopsy as in our case. The abdomino-pelvic scanner finds a mass on the duodenum [2], in touch with digestive tract [7] in continuity or not with the digestive tract with liquidor solid contents. If we look for an anomaly associated of the biliary tree, we can complete the imaging by a MRI for even the continuity with the biliary tract.

The treatment is surgical and gave greater place to the laparoscopy.

\section{References}

[1] Merrot, T., Anastasescu, R., Pankevych, T., et al. (2006) Duodenal Duplications. 
Clinical Characteristics, Embryological Hypotheses, Histological Findings, Treatment. European Journal of Pediatric Surgery, 16, 18-23.

https://doi.org/10.1055/s-2006-923798

[2] Alessandro, G., Faccioli, N., Ferrari, M., Romano, L., Parisi, A. and Falconi, M. (2006) Duodenal Duplication Cyst Causing Severe Pancreatitis: Imaging Findings and Pathological Correlation. World Journal of Gastroenterology, 12, 1630-1633. https://doi.org/10.3748/wjg.v12.i10.1630

[3] Borocco, A., Bosson, N., Ducou le Pointe, H., et al. (1996) A Case of Intrapancreatic Duodenal Duplication Communicating with the Biliopancreatic Channel. Journal de Radiologie, 77, 49-51.

[4] Puligandla, P.S., Nguyen, L.T., St-Vil, D., et al. (2003) Gastrointestinal Duplications. Journal of Pediatric Surgery, 38, 740-744. https://doi.org/10.1016/jpsu.2003.50197

[5] Antaki, F., Tringali, A., Deprez, P., et al. (2008) A Case Series of Symptomatic Intraluminal Duodenal Duplication Cysts: Presentation, Endoscopic Therapy, and Long-Term Outcome. Gastrointestinal Endoscopy, 67, 163-168. https://doi.org/10.1016/j.gie.2007.08.006

[6] Young Chul, J., Kwang Ro, J., Do Ha, K., et al. (2004) Duodenal Duplicated Cyst Manifested by Acute Pancreatitis and Obstructive Jaundice in an Elderly Man. Journal of Korean Medical Science, 19, 604-607. https://doi.org/10.3346/jkms.2004.19.4.604

[7] Rockx, J.M.A. and McAlister, V. (2007) Endoscopic Fenestration of a Duodenal Duplication Cyst to Resolve Recurrent Pancreatitis. Journal of the Pancreas, 28, 7958.

[8] Le Baleur, Y., Dhalluin-Venier, V., Thirot-Bidault, A., et al. (2007) Duodenal Duplication Revealed by Acute Pancreatitis: Endoscopic Treatment. Gastroenterologie Clinique et Biologique, 31, 670-671. https://doi.org/10.1016/S0399-8320(07)91916-8

[9] Vandenbroucke, F., Dagenais, M., Létourneau, R., Lapointe, R. and Roy, A. (2005) Endoscopic Treatment of a Duodenal Duplication Cyst. Endoscopy, 37, 601. https://doi.org/10.1055/s-2005-861328 